\title{
Prediction of difficult laryngoscopy in a population of Nigerian obstetric patients
}

\author{
*N. A. Merah', D. J. O. Foulkes-Crabbe', O. T. Kushimo' and P. A. Ajayi² \\ 'Department of Anaesthesia, College' of Medicine, University of Lagos \\ P. M. B. 12003, Lagos, Nigeria. \\ 'Surgeon, Chevron Hospital, Warri, Deta State, Nigeria.
}

\section{Summary}

Difficulty in the maintenance of the airway during obstetric anaesthesia is a major contributory factor in anaesthetic related morbidity and mortality. There is an eightfold increase in the incidence of failed intubation in obstetrics. This is attributable to the physiological changes in pregnancy.

Eighty consecutive obstetric patients, over a one year period who required general anaesthesia for caesarian section were evaluated using five bedside tests viz: Mallampati test, Thyrometal distance, Sterno-mental distance, Horizontal length of the Mandible and Inter-incisor gap.

Eight patients had difficult laryngoscopy (10\%). Mallampati test had a sensitivity, specificity and positive predictive value of $87.1 \%, 99.6 \%$ and $70 \%$ respectively. The values obtained for the Thyro-mental distance were $62.5 \%, 93.1 \%$ and $50 \%$ respectively. The other tests were not able to predict intubation difficulty significantly. When all tests were combined, sensitivity, specificity and positive predictive were values $100 \%, 36.1 \%$ and $14.8 \%$. The combination of Mallampati and Thyro-mental distance had values of $100 \%, 93.1 \%$ and $61.5 \%$ - sensitivity, specificity and positive predictive value.

Mallampati can be used as the sole predictor of difficult intubation in Nigerian obstetric patients.

Key words. Anaesthesia, Obstetric intubation, Tracheal complication, Difficult

\section{Résumé}

Le problème dans la prise en charge des bronches pendant l'anésthésie obstétrique est un des facteurs les plus importants qui contribuent à la morbidité et mortalité ayant rapport à l'anesthésie. Il y a une augmentation à l'octuple dans les cas de l'intubation échouée dans des obstétriques. Ceci est attributable au développement physiologique pendant la grossesse. Quatre vingt quatre patients obstétriques consecutifs, au cours d'une période d'une année, qui ont besoin de l'anesthésie générale pour la césarienne ont été évalués avec l'utilisation de cinq tests de chevet a savoir: Test Mallampati, Thyromental a distance, sterno-mental à distance, longueur horizontale de la machoirenet le vide inter-incisive.

Huit patients avaient le problème laryngescopie soit $10 \%$. Test Mallapati avait la sensibilité, specificité et une valeure positive prophetique. Les autres tests ne pouvaient pas sensiblement predire le problème lié a l'intubation. Quand on avait réuni tous les tests, les valeurs de la sensitivité, spécificité et prophétique positive étaient $100 \%, 36.1 \%$ et $14,8 \%$. La combinaison de Mallampati et Thyro-mental à distance avaient des valeurs de $100 \%, 93.1 \%$ et $61,5 \%=$ sensitivité spécificité et la valeur positive prophétique. On peut utiliser Mallampati comme la seule prédiction de l'intubation difficile chez des patients obstétriques Nigerians.

\section{Introduction}

Difficult or failed tracheal intubation, often unexpected has been identified as the most common contributory factor to anaesthetic-related maternal death. ${ }^{1,2}$ The incidence of difficult tracheal intubation is not precisely known but failed tracheal intubation has been reported to be eight times greater in the obstetric patients when compared to other surgical patients $^{3,4}$ Contributory anatomical factors among obstetric patients include laryngeal edema, large pendulous breasts and obesity. Risk factors identified at the preoperative visit have been used to alert the Anaesthesiologist so that alternative methods of securing the airway can be used or additional experienced support obtained. Although many tests have been described, the results vary from one study to another. Therefore, it has not been possible to form a judgment as to which test is the best predictor of difficult intubation.

The purpose of this study was to compare the bedside screening tests for difficult intubation described by various authors in terms of their sensitivities, specificities and positive predictive values in a sample of Nigeria Obstetric Patients.

\section{Materials and methods}

After institutional approval by the Research and Ethics Board (REB) of the Lagos University, Teaching Hospital, 80 consecutive obstetric patients, American Society of Anaesthesiologist physical status 1 to 3 who needed general anaesthesia for caesarian section were studied. Exclusion criteria included inability to sit, gross anatomical abnormality of head and neck or recent surgery involving those areas and patients with severe cardio respiratory disorders. A senior anaesthetist with 4 years experience in the practice of anaesthesia performed the evaluation preoperatively and the various parameters were documented in a proformer for each patient.

The five bedside tests that were evaluated are Mallampati Tests, Thyro-Mental Distance (TMD), SternoMental Distance (SMD) Horizontal Length of the Mandible (HLM) and the Inter-Incisor Gap (IIG).

1. Samsoon and Young's modification of the Mallampati Test $^{5}$ was employed viz.

The patient was seated with the head in the neutral position and asked to open the mouth fully and protrude the tongue maximally while the observer looked from the front at the patient's eye level and inspected the pharyngeal 
structures with a pen torch without the patient phonating. The view was graded as follows:

i. Soft palate, uvula, fauces and pillars visible.

ii. Soft palate, uvula (base), fauces but pillars invisible

iii. Soft palate visible

iv. Soft palate invisible.

Difficulty was predicted with grades III and IV.

\section{Thyro-mental distance, (Patil's Distance)}

The patient was seated upright and asked to extend his/ her head and neck as far as possible with mouth closed. The straight distance on the exterior surface from the inside of the mentum to the thyroid notch was measured.

Difficulty was predicted when the distance was $\leq 6.5 \mathrm{~cm}$

\section{Horizontal Length of the mandible}

The patient was seated with the head in the neutral position. The straight distance from the angle of mandible to the symphysis-menti was measured. If the distance was less than $9 \mathrm{~cm}$, intubation was anticipated to be difficult.

\section{Sterno-mental Distance (Savva's distance) ${ }^{\mathrm{x}}$}

This distance was measured in the seated position with the head fully extended on the neck and with the mouth closed. The straight distance between the upper border of the manubrium-sterni and bony point of the mentum was measured. If the distance was $13.5 \mathrm{~cm}$ or less, intubation was predicted as difficult.

*Tests 2 - 4 were performed with a rigid ruler.

\section{The Inter-Incisor Gap}

The patient was asked to open the month as wide as possible and the distance between the upper and lower incisor measured with a pair of calipers. The critical value chosen was $2.5 \mathrm{~cm}$.

\section{Induction}

Induction of anaesthesia was performed in the supine position and neuromuscular blocking agent administered using a technique appropriate for the individual patient and clinical circumstance. The patient's head was placed on a pillow in the 'sniffing position' i.e. flexion of the neck and extension of the head at the atlanto-occipital joint. Repeated induction was carried out with thiopentone and suxamethonium for those patients that were difficult to intubate.

A single operator using a Macintosh \#4 blade performed laryngoscopy and best view obtained (external laryngeal pressure was not applied) using the classification by Cormack and Lehane 9

i. Vocal cords visible

ii. Only posterior commisure or arytenoids visible

iii. Only epiglottis visible

iv. None of the foregoing visible.

A note was made if tracheal intubation was difficult i.e. if the view at laryngoscopy was graded Cormack-Lehane III or IV. Accuracy of each measured parameter was scored against the Cormack Lehane outcome. Values below and inclusive of each cut-off point were predicted as difficult intubation for the (Easy-to-Intubate: EIG). In the case of
Mallampati Score, Mallampati l and II were predicted as easy intubation while III and IV as difficult intubation (Difficultto-Intubate: DIG).

Confirmation of successful intubation was by bilateral auscultation over the lung fields and capnography when available.

\section{Definitions $^{10}$}

The sensitivity, specificity and positive predictive value of each test was calculated as follows using Cormack Lehane Score as the constant variable.

Sensitivity $=$ the percentage of correctly predicted difficult intubation as a proportion of all intubations that were truly difficult i.e.

\section{True Positives}

True Positives + False Negatives

Specificity $=$ the percentage of correctly predicted easy intubations as a proportion of intubations that were truly easy i.e.

True Negatives

\section{True Negatives + False Positives}

\section{Positive predictive}

Value $=$ the percentage of correctly predicted difficult intubations as a proportion of all predicted difficult intubations, i.e.

\section{True positive \\ True positives + false positives.}

The data obtained was analyzed with the aid of a computer software; statistical package for social studies (SPSS @ Inc. Chicago Illinois).

\section{Results}

A total number of 80 of the obstetric patients were studied $(\mathrm{n}=80)$. Their mean age, height, weight and BMI were $30.9 \pm$ 4.4 years; $1.6 \pm 0.5 \mathrm{~m} ; 83.8 \pm 14.6 \mathrm{~kg}$ and $31.2 \pm 5.5$ respectively. Out of the 69 patients who had a Cormack-Lehane score of 1 , $51(74 \%)$ had a corresponding Mallampati $1 ; 15(21.7 \%)$ had Mallampati II and 3 patients (4.3\%) had Mallampati III. There was no Mallampati IV in this category (Table 1).

The mean values of the quantitative predictive tests were as follows - SMD had a mean distance of $17.8 \pm 1.7 \mathrm{~cm}$; TMD had a mean distance of $7.5 \pm 1.0 \mathrm{~cm}$; IIG had a mean of $4.3 \pm$ $0.6 \mathrm{~cm}$ and HLM a mean of $9.1 \pm 0.3 \mathrm{~cm}$.

\section{Predictive tests of easy-to-intubate (EIG) and difficult-to-intubate (DIG)}

Based on the Cormack-Lehane scores the 80 obstetric patients were sub-divided into EIG (Cormack-Lehane I and II) and DIG (Cormack-Lehane III and IV). Table II illustrates the mean values of their biodata. There was a significant difference between the means of the weight and BMI in the EIG and DIG $(p=000)$ - see Table II

Table III shows the means of the predictive tests in both patient categories. A p-value of 0.011 was obtained between the EIG and DIG for Thyro-mental distance.

TMD was able to predict 5 out of the $8(62.5 \%)$ in the DIG 
Table I Cormack-Lehane scores of obstetrics subjects related to Mallampati assessment

\begin{tabular}{lccccc}
\hline & \multicolumn{5}{c}{$\begin{array}{c}\text { Mallampati score } \\
\text { (Value + Row \%) }\end{array}$} \\
$\begin{array}{l}\text { Cormack }- \\
\text { Lehane }\end{array}$ & $\mathbf{1}$ & $\mathbf{2}$ & $\mathbf{3}$ & $\mathbf{4}$ & Total \\
1 & $51(74 \%)$ & $15(21.7 \%)$ & $3(4.3 \%)$ & 0 & $\mathbf{6 9}(86.25 \%)$ \\
2 & 0 & $3(100 \%)$ & 0 & 0 & $3(3.75 \%)$ \\
3 & 0 & $1(16.6 \%)$ & $6(83.4 \%)$ & 0 & $7(8.75 \%)$ \\
4 & 0 & 0 & $1(100 \%)$ & 0 & $1(1.25 \%)$ \\
Total & 51 & 19 & 10 & 0 & $80(100 \%)$ \\
\hline
\end{tabular}

Table 2 Means of obstetric patient's biodata grouped by Cormack-Lehane score

\begin{tabular}{cccl}
\hline & Cormach-Lehane scores & \multicolumn{2}{c}{ Cormack-Lehane Score } \\
Biodata & $\mathbf{1} \& \mathbf{2}$ & $\mathbf{3} \& \mathbf{4}$ & \\
Age (Years) & $30.9 \pm 4.3$ & $30.8 \pm 5.8$ & 0.907 \\
Height $(\mathrm{m})$ & $1.6 \pm 0.05$ & $1.6 \pm 0.05$ & 0.398 \\
Weight $(\mathrm{kg})$ & $81.0 \pm 12.0$ & $109.1 \pm 12.4$ & $0.000^{* *}$ \\
BMI & $30.5 \pm 4.7$ & $39.9 \pm 4.9$ & $0.000^{* *}$ \\
\hline
\end{tabular}

** Statistically significant

Table 3 Means of predictive tests in obstetric subjects grouped by Cormack-Lehane score

\begin{tabular}{lccc}
\hline \multicolumn{4}{c}{ Cormack-Lehane Cormach-Lehane } \\
$\begin{array}{l}\text { Predictive } \\
\text { Test (cm) }\end{array}$ & $\begin{array}{c}\text { Scores 1 \& 2 } \\
(\mathbf{n}=72)\end{array}$ & $\begin{array}{c}\text { Scores 3 \& 4 } \\
(\mathbf{n}=8)\end{array}$ & P-Value \\
$\begin{array}{l}\text { Sterno-mental } \\
\text { Distance }\end{array}$ & $17.8 \pm 1.6$ & $17.2 \pm 2.0$ & 0.279 \\
$\begin{array}{l}\text { Thyro-mental } \\
\text { Distance }\end{array}$ & $7.6 \pm 1.0$ & $6.6 \pm 0.6$ & $0.011^{*}$ \\
$\begin{array}{l}\text { Inter-Incisor Gap } \\
\text { Horizontal Length } \\
\text { of Mandible }\end{array}$ & $4.3 \pm 0.6$ & $3.9 \pm 0.6$ & 0.092 \\
\hline$* *$ Stunstically significunt & $9.1 \pm 0.3$ & $9.0 \pm 0.3$ & 0.412 \\
\hline
\end{tabular}

Table 4 Predictive trends in the parameters in Obstetric subjects

\begin{tabular}{lcccc}
\hline $\begin{array}{l}\text { Predictive } \\
\text { test }\end{array}$ & $\begin{array}{c}\text { True } \\
\text { positive } \\
(\mathbf{n = 8 )}\end{array}$ & $\begin{array}{c}\text { False } \\
\text { positive } \\
(\mathbf{n}=\mathbf{7 2})\end{array}$ & $\begin{array}{c}\text { True } \\
\text { negative } \\
(\mathbf{n}=72)\end{array}$ & $\begin{array}{c}\text { False } \\
\text { negative } \\
(\mathbf{n = 8}=\mathbf{8})\end{array}$ \\
TMD & $5(62.5 \%)$ & $5(6.9 \%)$ & $\mathbf{6 7}(93.1 \%)$ & $3(37.5 \%)$ \\
SMD & $\mathbf{0 ( 0 \% )}$ & $\mathbf{0 ( 0 \% )}$ & $72(100 \%)$ & $8(100 \%)$ \\
IIG & $\mathbf{0 ( 0 \% )}$ & $\mathbf{0 ( 0 \% )}$ & $72(100 \%)$ & $8(100 \%)$ \\
HLM & $\mathbf{4}(50.0 \%)$ & $46(63.9 \%)$ & $26(36.1 \%)$ & $4(50.0 \%)$ \\
Mallampati & $7(87.5 \%)$ & $3(4.2 \%)$ & $69(95.8 \%)$ & $1(12.5 \%)$ \\
\hline
\end{tabular}

Table 5 Test parameters in the obstetric population: sensitivity, specificity and positive predictive value

\begin{tabular}{lccc}
\hline $\begin{array}{l}\text { Predictive } \\
\text { tests }\end{array}$ & Sensitivity (\%) & Specificity (\%) & $\begin{array}{c}\text { Positive } \\
\text { Predictive } \\
\text { Value (\%) }\end{array}$ \\
TMD & 62.5 & 93.1 & 50 \\
SMD & 0 & 100 & 0 \\
IIG & 0 & 100 & 0 \\
HLM & 50 & 36.1 & 7.7 \\
Mallampati & 87.5 & 95.8 & 70 \\
\hline
\end{tabular}

at the same time falsely predicting 5 out of $72(6.9 \%)$. Mallampati was able to predict $7(87.5 \%)$ in DIG while falsely predicting $3(4.2 \%)$ cases. HLM was able to predict $4(50 \%)$
Table 6 Sensitivity, specificity and positive predictive value of the combined test parameters in the obstetric population

\begin{tabular}{|c|c|c|c|}
\hline $\begin{array}{c}\text { Test } \\
\text { combination }\end{array}$ & $\begin{array}{c}\text { Sensitivity } \\
(\%)\end{array}$ & $\begin{array}{c}\text { Specificity } \\
(\%)\end{array}$ & $\begin{array}{c}\text { Positive } \\
\text { predictive } \\
\text { value }\end{array}$ \\
\hline $\begin{array}{l}\text { Mallampati + } \\
\text { SMD + TMD } \\
\mathrm{IIG}+\mathrm{HLM}\end{array}$ & 100 & 36.1 & 14.8 \\
\hline $\begin{array}{l}\text { 2. Mallampati }+ \\
\text { TMD }\end{array}$ & 100 & 93.1 & 61.5 \\
\hline 3. Mallampati & 87.5 & 95.8 & 70 \\
\hline
\end{tabular}

while falsely predicting $46(63.9 \%)$. SMD and IIG however had no predictive values. See Table IV.

The sensitivity, specificity and the positive predictive value of the test parameters were calculated. (Table V). Mallampati had the highest values: $87.5 \% ; 95.8 \%$ and $70 \%$ respectively. Next were the values obtained by the TMD, which were $62.5 \% ; 93.1 .5 \%$ and $50 \%$. HLM had values of $50 \% ; 36.1 \%$ and $7.7 \%$. When all the tests were combined, all the cases in the DIG were predicted. The five-test combination however falsely predicted 46 (63.9\%). The combination of Mallampati and TMD also predicted all the cases in the DIG while falsely predicting $5(6.9 \%)$ cases.

The combined sensitivity of all the tests was $100 \%$, while the specificity was $36.1 \%$ and the positive predictive value was $14.8 \%$. The combination of Mallampati and TMD had a sensitivity of $100 \%$; specificity $93.1 \%$ and positive predictive value of $61.5 \%$. (Table VI).

\section{Discussion}

A screening test for the prediction of difficult laryngoscopy must be rapid and provide reliable results. No single screening test is $100 \%$ sensitive and $100 \%$ specific. A test to predict difficult laryngoscopy should have a high positive predictive value, so that only a few patients with airways actually easy to intubate are subjected to the protocol for management of a difficult airway. Inevitably some difficult laryngoscopies are not predicted and also false positives occur, but they must be as few as possible.

Difficult laryngoscopy was defined by the ASA task force as occuring when "it is not possible to visualize any part of the vocal cord with conventional laryngoscopy." This would equate to grade III or IV laryngoscopy of the CormackLehane classification.

The five tests used in this study included Mallampati test, Sterno-Mental distance, Thyro-Mental distance, the Horizontal length of the Mandible and the Inter-incisor gap. The Mallampati test has often been criticized for it's low

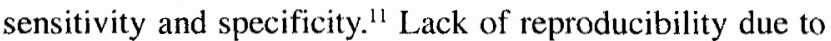
interobserver variation has been another problem noted by a lot of our colleagues. We found this test very useful amongst our obstetric patients after carefully carrying out the test described by Mallampati. Provided the patient is not gagging or phonating, the view should be constant and a clearly defined grading system should make the tests reproducible. ${ }^{12}$ Careful methodology would explain the sensitivity, specificity 
and positive predictive value of $87.5 \%, 95.8 \%$ and $70 \%$ respectively, which is comparable with the work done by Mallampati et al in an American population ${ }^{5}$ and Ita, Eshiet and Akpan in Calabar, Nigeria. ${ }^{13}$ Frerk had a sensitivity of $81.2 \%$ and specificity $81.5 \%$ which could be compared to the results in this study. ${ }^{6}$

The Sterno-mental distance could not predict any of the difficult laryngoscopies. This could be attributed to the cutoff point of $13.5 \mathrm{~cm}$, which was used in this study. Savva ${ }^{8}$ who first used the test to predict difficult laryngoscopy and intubation used a distance of $12.5 \mathrm{~cm}$. Ramadhani and colleagues $^{14}$ subjected the cut off point to discriminate analysis and they used a distance of $13.5 \mathrm{~cm}$, as their cut-off point. The mean distance of the EIG was $18.5 \pm 2.1 \mathrm{~cm}$ while the mean distance in the DIG was $17.1 \pm 1.9 \mathrm{~cm}$. A possible cause of these differences in mean values could be attributed to anthropometrical differences between people from the Middle East and West Africa. It is hoped that further research should shed more light on this observation. Although the cut-off point for the Thyro-mental distance was $6.5 \mathrm{~cm}$, it was found to be useful in the prediction of the difficult laryngoscopies. The differences in the means between the DIG (6.6. $\pm 0.6 \mathrm{vm})$ and the EIG (7.6 \pm 1.6$)$ were statistically significant $(p=0.011)$. This might be another pointer that anthropometrical differences may have a role to play. Weight contributed to the prediction of difficult laryngoscopy. The differences between the means of the DIG $(109.1 \pm 12.4 \mathrm{~kg})$ and the EIG $(81 \pm 12.0 \mathrm{~kg})$ were statistically significant $(\mathrm{p}=$ 0.000 ). The Inter-incisor gap and the horizontal length of the mandible were not found useful in the prediction of the difficult laryngoscopies. When all the tests were combined, all the difficult laryngoscopies were predicted but at the expense of a very low specificity $(36.1 \%)$ and positive predictive value (14.8\%). When the Mallampati test and the Thyro-mental distance were combined $100 \%$ sensitivity was achieved but the specificity dropped to $93.1 \%$ and the positive predictive value dropped to $61.5 \%$ from $70 \%$. Perhaps a larger sample size could have made a difference in the results obtained. In conclusion we find a strong correlation between the Mallampati test and prediction of difficult laryngoscopy. The advantage of this method is that it can easily be performed at the bedside. It is always better to be prepared for difficulty beforehand than be caught in unexpected difficulty.

\section{References}

1. Chestnut DH: Anaesthesia and maternal mortality.
Anesthesiology 1997; 86: $273-6$.

2. Report on confidential enquiry into maternal deaths in Great Britain in 1994 - 96. London. HMSO, DHSS 1999.

3. Hawthorne L, Wilson R, Lyons G, Dresner M: Failed intubation revisited: $17 \mathrm{yr}$ experience in a teaching maternity unit. Br. J Anesthesia 1996; 76: $680-684$.

4. Rocke DA, Murray WB, Rout CC, Gouws E: Relative risk analysis of factors associated with difficult intubation in obstetric anaesthesia. Anaesthesiology 1992; 77: $67-73$.

5. Mallampati SR, Gatt SP, Gugino LD, Desai SP and Waraska B et al: A clinical sign to predict difficult tracheal intubation: A prospective study. Can anaesth Soc. J 1985; 32: 429 - 34 .

6. Freck CM: Predicting difficult intubation. Anaesthesia 1991; 46: $1005-6$.

7. Matthew M, Hanna LS and Aldrete JA: Pre-operative indices to anticipate difficult tracheal intubation. Anesth. Analg, 1989; 68: $\$ 187$.

8. Savva D: Prediction of difficult tracheal intubation. $\mathrm{Br} \mathbf{J}$. Anaesth. 1994; 73: 149 - 53.

9. Cormach RS and Lehane J: Difficult tracheal intubation in obstetrics. Anaesthesia 1984; 39: $1105-11$.

10. Tse JC, Rimm EB and Hussain A: Predicting difficult intubation in surgical patients for general anaesthesia: A prospective Blind Study. Anaeth. Analg 1995; 81: $254-8$.

11. Karkouti K, Rose KD, Ferris LE and Meisamai-Fard T: Interobserver reliability of ten tests used for predicting difficult intubation. Can J Anaesth 1996; 43: 554 - 9.

12. Tham EJ, Gildersleve CD, Sanders LD, Mapleson WW and Vaughan RS: Effects of posture, phonation and observer on Mallampati classification. Br. J. Anaesth. 1992; 68: 32 - 8 .

13. Ita CE, Eshiet AI and Akpan SG: Recognition of the difficult airway in normal Nigerian adults. West African Journal of Medicine Vol. 13, Nop. 2, April - June, 1994.

14. Ramadhani SAL, Mohammed LA, Rocke DA and Gouws EL Sternomental distance as the sole predictor of difficult laryngoscopy in obstetric Anaesthesia Br. J. Anaesth. 1996; 77: $312-316$. 